\title{
Voluntary supplementation does not fully correct iodine deficiency among Latvian pregnant women: a national cross-sectional survey
}

Dace Teterovska, Anna Jekabsone, Elina Tetere, leva Kalere, leva Strele, Maija Dambrova, Marina Makrecka, Rudolfs Mezhapuke, Vija Veisa, Didzis Gavars, Ilze Konrade

\section{Introduction}

Low iodine intake during pregnancy may cause thyroid dysfunction, which might result in an inadequate foetal brain development. Although Latvia has been considered iodine replete, newborn TSH screening data suggest some iodine deficiency. In the absence of universal salt iodization programme we conducted a nation-wide study of pregnant women from all regions of Latvia.

\section{Methods}

The study enrolled 829 pregnant women. They were asked to fill a questionnaire on dietary habits concerning iodine intake $(n=745)$. Thyroid function (TSH, FT4) and antibodies (antiTPO-Ab) were measured $(n=630)$. Urinary iodine was measured with ammonium persulfate method $(n=743)$.

The median urinary iodine conce
$80.8($ IQR 46.1-130.6) $\mu \mathrm{g} / \mathrm{g} \mathrm{Cr}$
$\mathbf{6 9 . 4}(\mathrm{IQR}=53.9-92.5) \mu \mathrm{g} / \mathrm{I}$

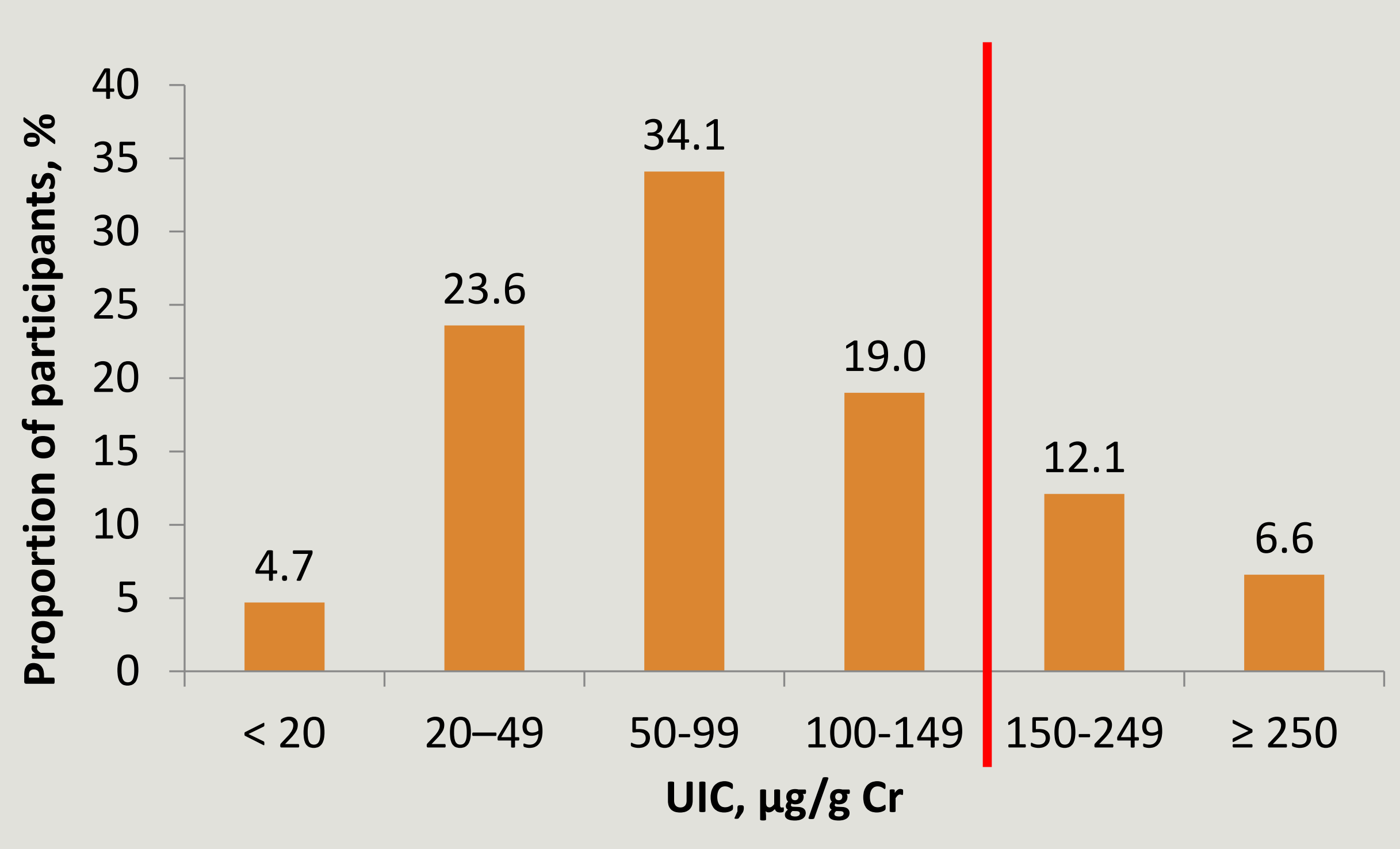

UIC was the lowest during the first trimester $(p<0.001)$

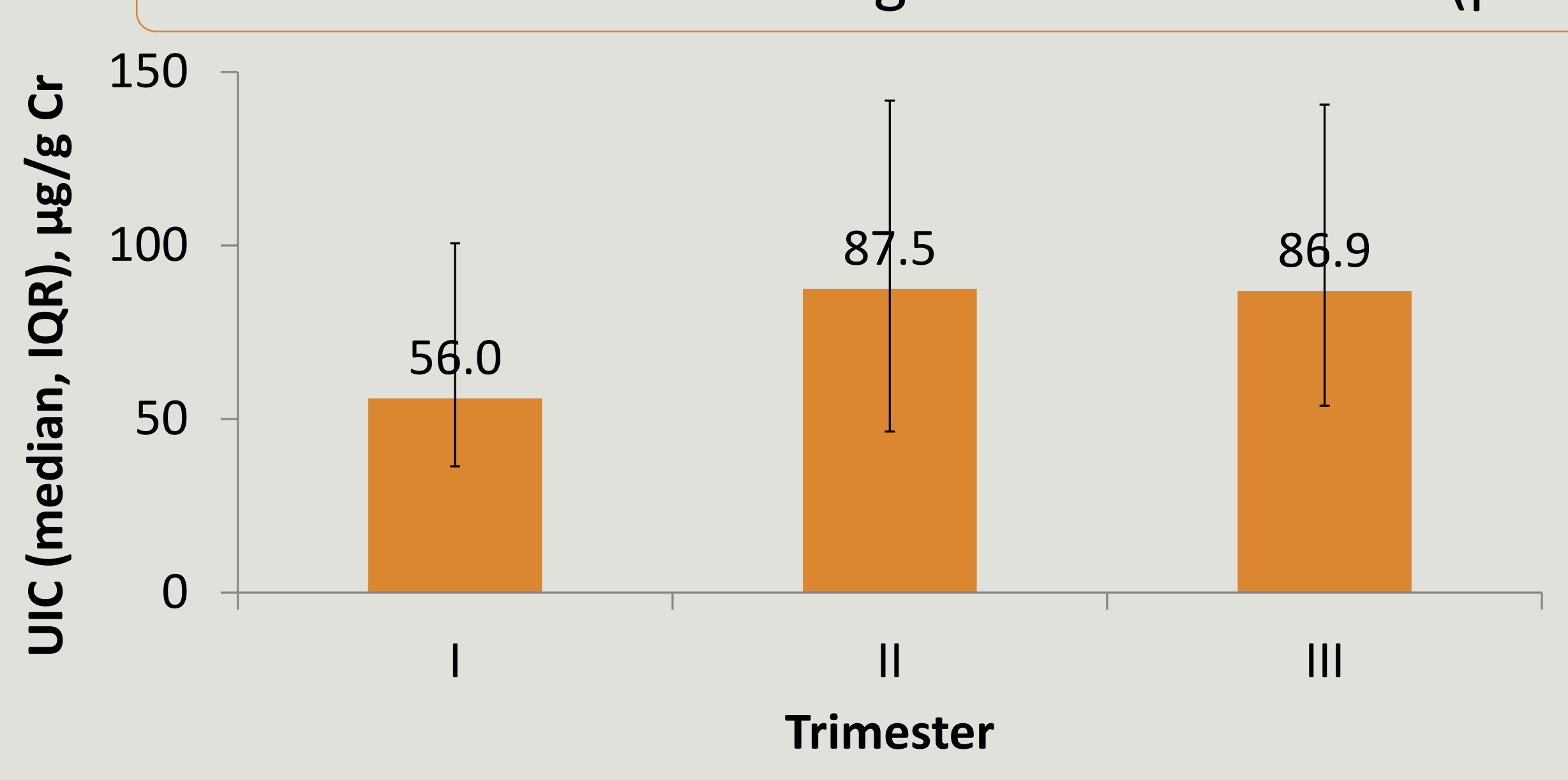

Urinary iodine concentration did not correlate with anti-TPO antibody concentration

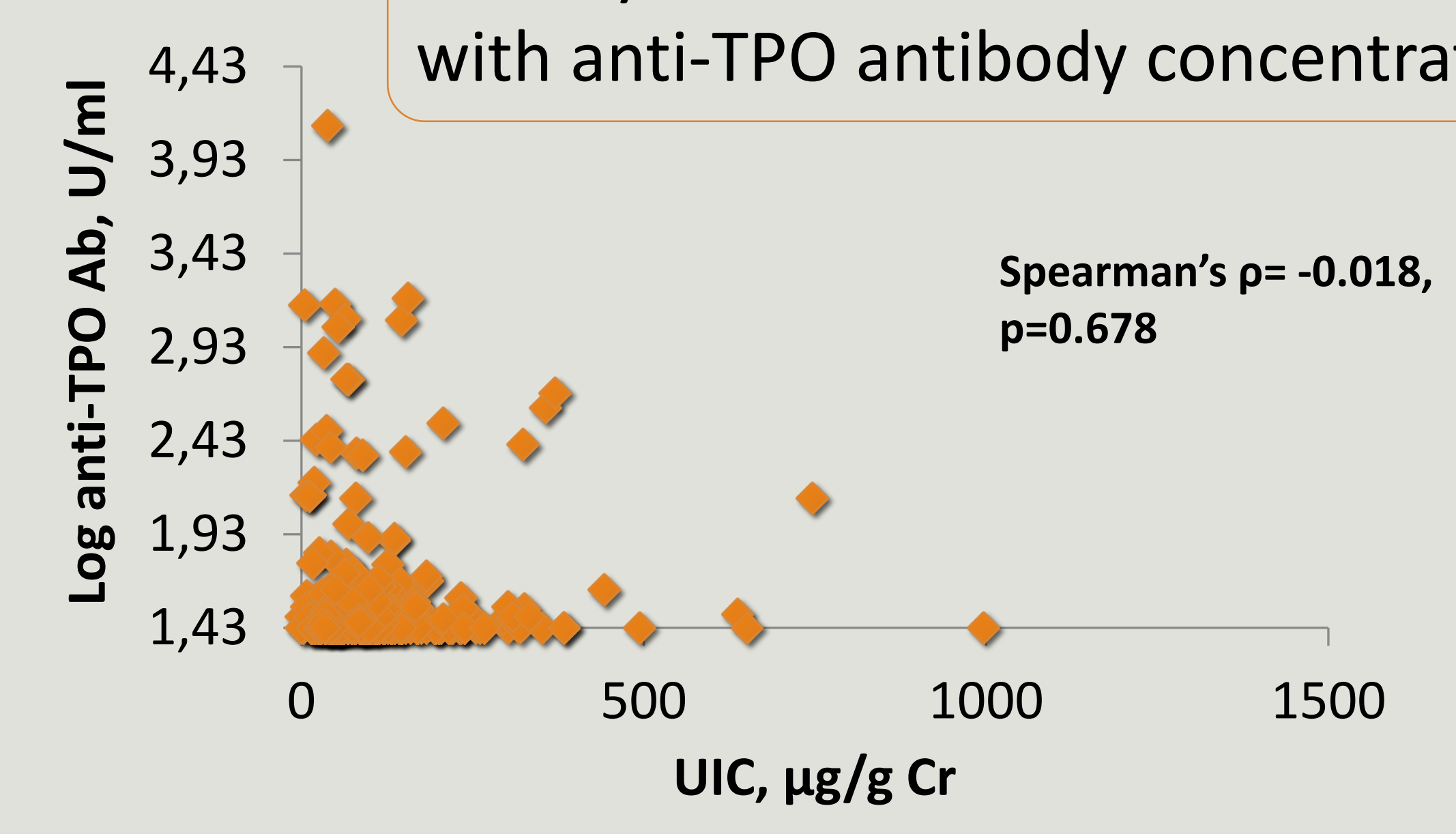

\section{Results}

lodine sources

- lodine containing supplements

- lodized salt

- Sea fish

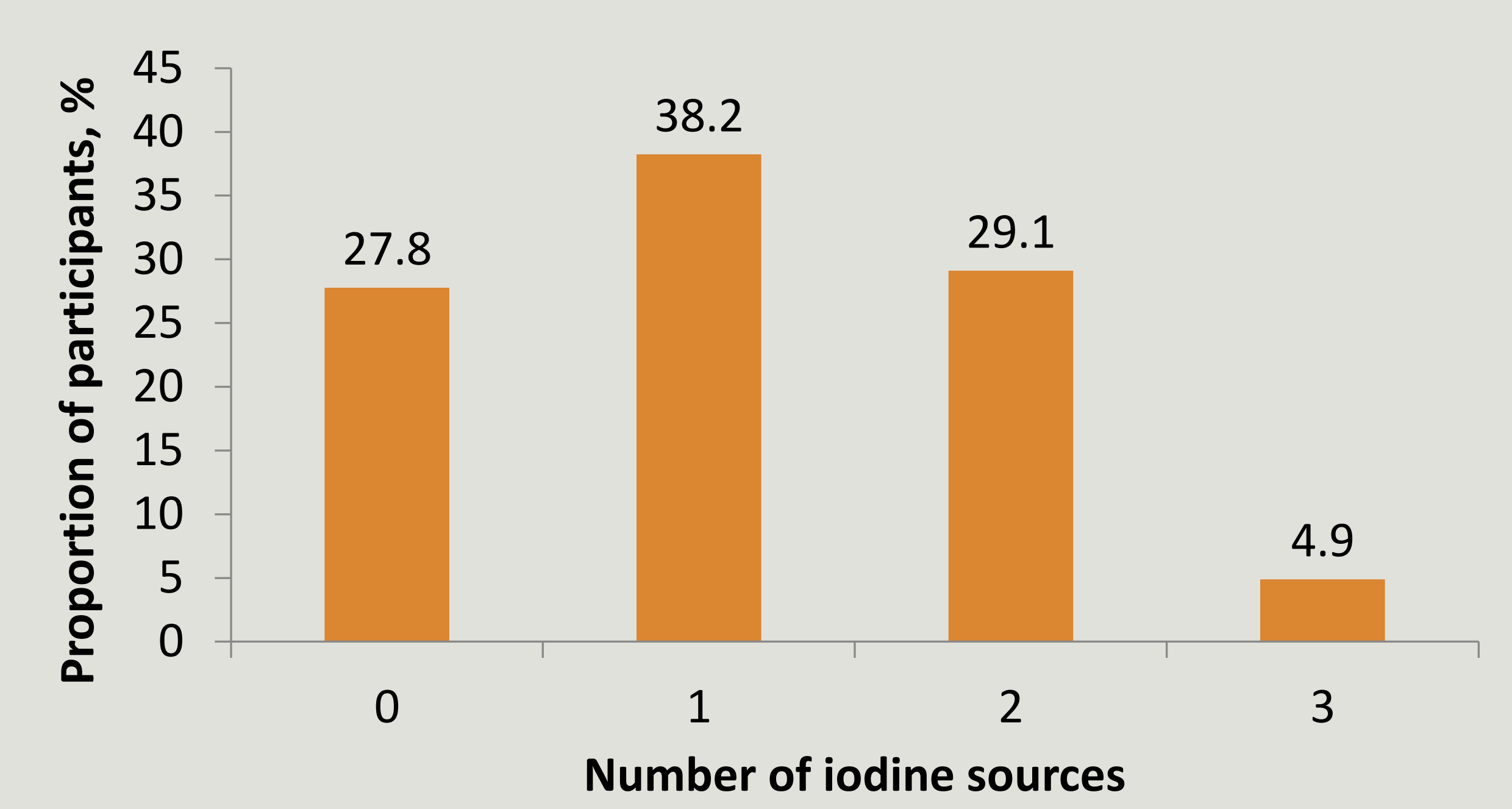

Regular dietary supplement consumption during the current pregnancy was reported by $61.8 \%$ of participants

- Of those $30.4 \%$ had iodine containig supplements

- $11.2 \%$ of participants had supplements with iodine content $\geq 150 \mu \mathrm{g}$

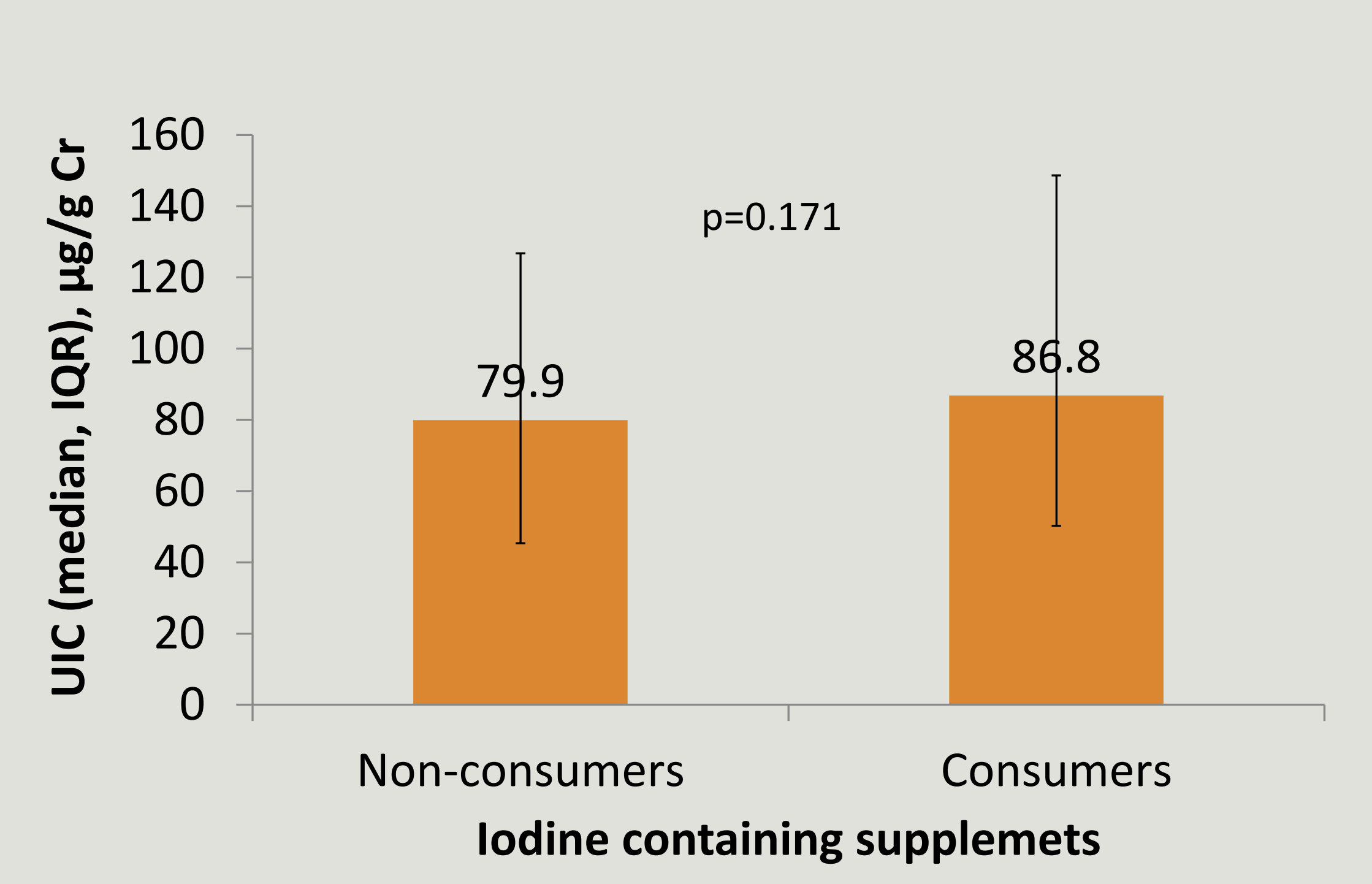

WHO criteria for assessing iodine nutrition based on median UIC

\begin{tabular}{|c|c|}
\hline Iodine intake & Median UIC $(\mu g / I)$ \\
\hline Insufficient & $<150$ \\
\hline Adequate & $150-249$ \\
\hline $\begin{array}{c}\text { Above } \\
\text { requirements }\end{array}$ & $250-499$ \\
\hline Excessive & $>500$ \\
\hline
\end{tabular}

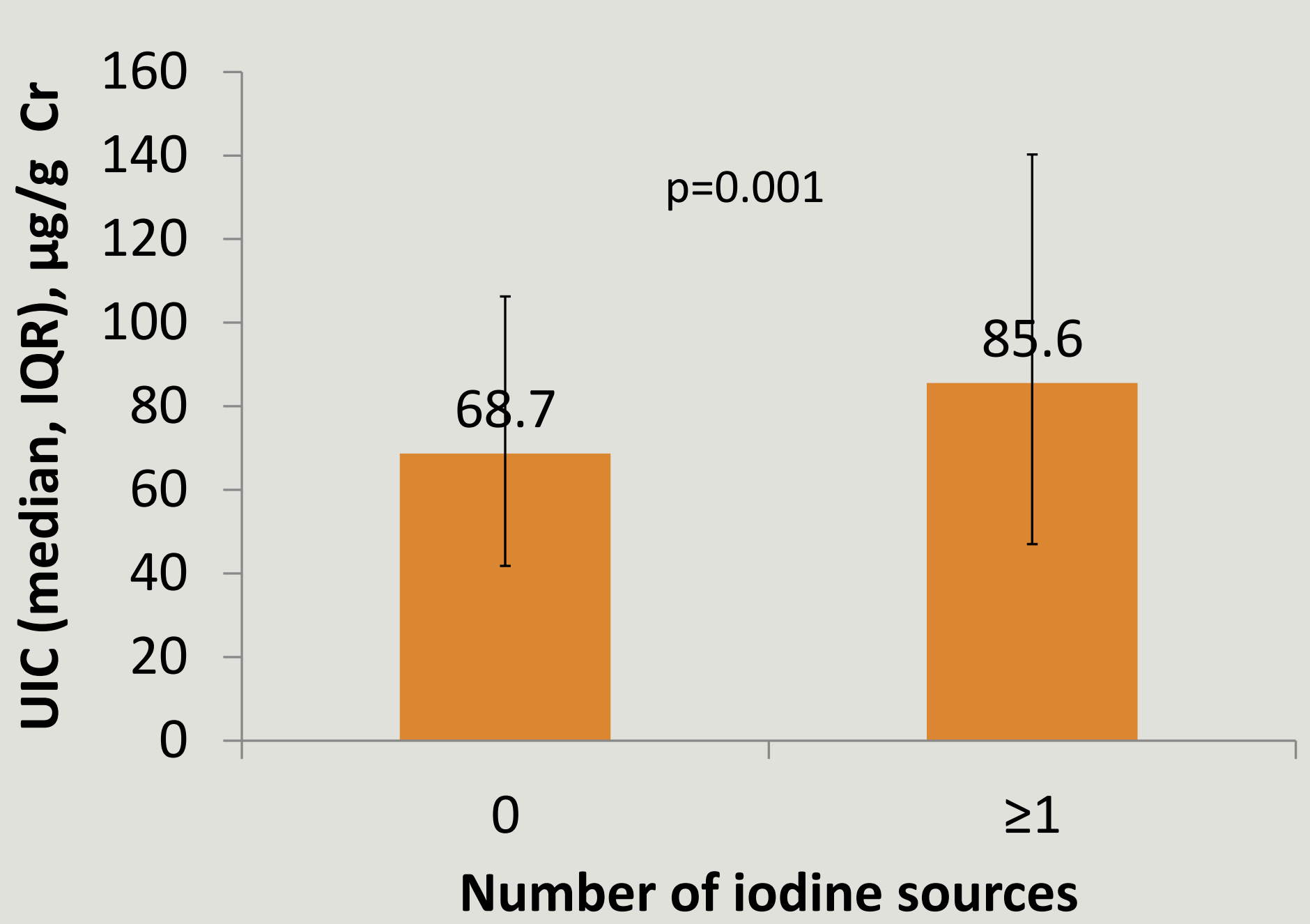

The self-reported prevalence of iodized salt consumption was $45 \%$.

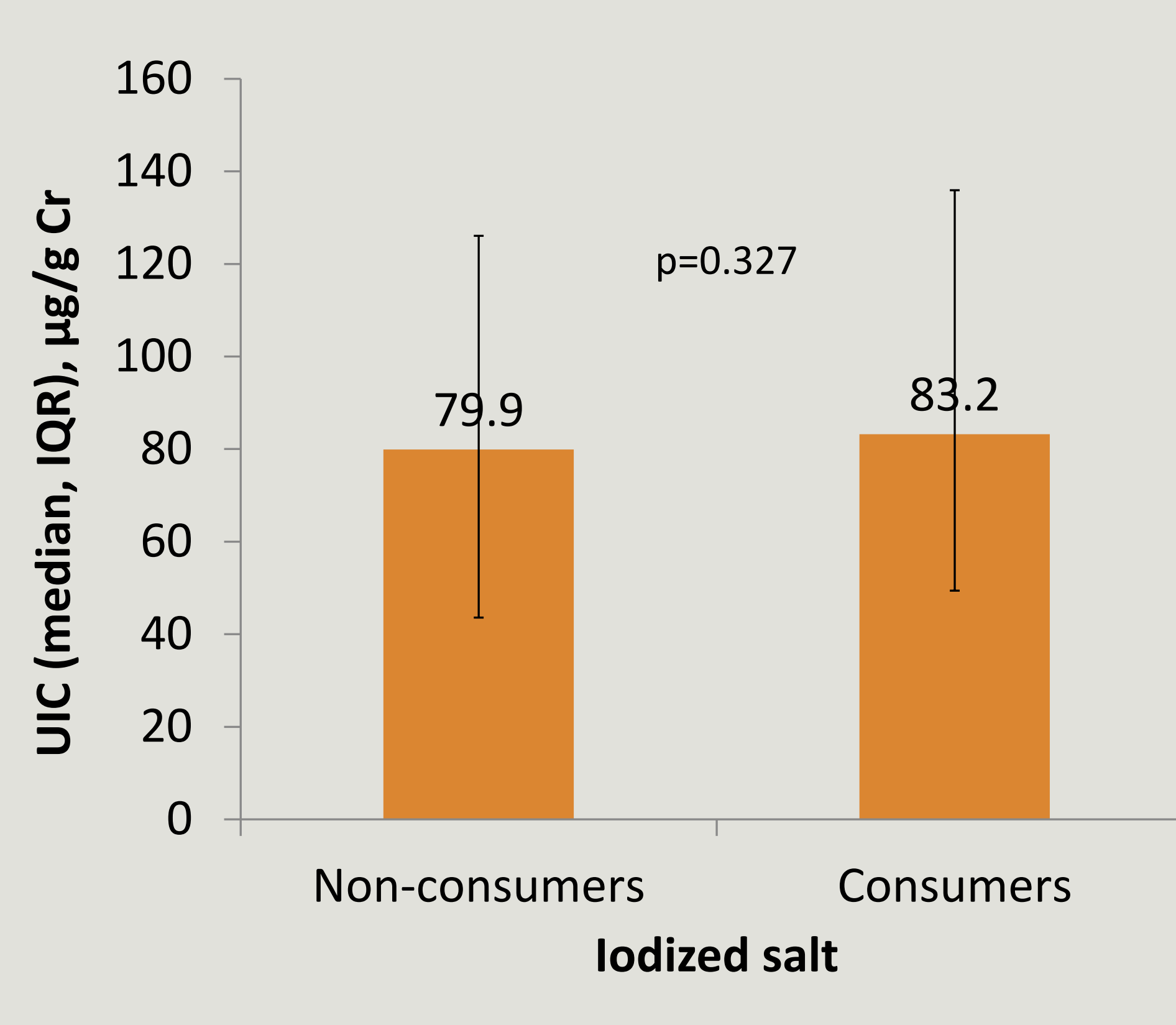

\section{Conclusion}

The median UIC indicates iodine deficiency in pregnant women in Latvia. Correction of iodine deficiency with $150 \mu \mathrm{g}$ iodine daily should be considered for recommendation. 